Article

\title{
Evaluation of Low-Head Ramped Weirs for a Potamodromous Cyprinid: Effects of Substrate Addition and Discharge on Fish Passage Performance, Stress and Fatigue
}

\author{
Susana D. Amaral ${ }^{1, * \mathbb{D}}$, Paulo Branco ${ }^{1} \mathbb{D}$, Filipe Romão ${ }^{2} \mathbb{D}$, Maria Teresa Ferreira ${ }^{1} \mathbb{D}$, António N. Pinheiro ${ }^{2} \mathbb{D}$ and \\ José Maria Santos $1, * \mathbb{D}$ \\ 1 Forest Research Centre, School of Agriculture, University of Lisbon, Tapada da Ajuda, 1349-017 Lisboa, \\ Portugal; pjbranco@isa.ulisboa.pt (P.B.); terferreira@isa.ulisboa.pt (M.T.F.) \\ 2 CERIS-Civil Engineering for Research and Innovation for Sustainability, Técnico, University of Lisbon, \\ Avenida Rovisco Pais, 1049-001 Lisboa, Portugal; filipe.romao@tecnico.ulisboa.pt (F.R.); \\ antonio.pinheiro@tecnico.ulisboa.pt (A.N.P.) \\ * Correspondence: samaral@isa.ulisboa.pt (S.D.A.); jmsantos@isa.ulisboa.pt (J.M.S.); \\ Tel.: +351-213653489 (J.M.S.)
}

\section{check for} updates

Citation: Amaral, S.D.; Branco, P.; Romão, F.; Ferreira, M.T.; Pinheiro, A.N.; Santos, J.M. Evaluation of Low-Head Ramped Weirs for a Potamodromous Cyprinid: Effects of Substrate Addition and Discharge on Fish Passage Performance, Stress and Fatigue. Water 2021, 13, 765. https:// doi.org/10.3390/w13060765

Academic Editor:

Bommanna Krishnappan

Received: 5 February 2021

Accepted: 9 March 2021

Published: 11 March 2021

Publisher's Note: MDPI stays neutral with regard to jurisdictional claims in published maps and institutional affiliations.

Copyright: (c) 2021 by the authors. Licensee MDPI, Basel, Switzerland. This article is an open access article distributed under the terms and conditions of the Creative Commons Attribution (CC BY) license (https:// creativecommons.org/licenses/by/ $4.0 /)$.

\begin{abstract}
Requalification of low-head ramped weirs through the addition of substrates (retrofitting) has attracted attention in recent years. However, few studies are available on how this measure affects the negotiation of ramped weirs by fish. This study aimed to assess the performance of an experimental ramped weir ( $3.00 \mathrm{~m}$ long with $10 \%$ slope; $0.30 \mathrm{~m}$ head-drop) to enhance the passage of a potamodromous cyprinid species, the Iberian barbel (Luciobarbus bocagei). Attention was given to testing the effects of the addition of a substrate, in this case cobbles, to the ramp (Nature) vs. a smooth bottom (Control), and discharge $\left(\mathrm{Q} ; 55 \mathrm{~L} \cdot \mathrm{s}^{-1}\right.$ and $110 \mathrm{~L} \cdot \mathrm{s}^{-1}$ (or specific discharge per unit width, $\mathrm{q}=92 \mathrm{~L} \cdot \mathrm{s}^{-1} \cdot \mathrm{m}^{-1}$ and $\left.183 \mathrm{~L} \cdot \mathrm{s}^{-1} \cdot \mathrm{m}^{-1}\right)$ ) on fish passage performance. Fish physiological responses to stress and fatigue, measured by glucose and lactate concentrations in blood samples, were also analysed. Results showed that the Nature design generally increased fish movements and successful upstream passages, and enhanced fish passage performance by enabling faster negotiations. Fish movements were also affected by increasing discharge, registering reductions with $110 \mathrm{~L} \cdot \mathrm{s}^{-1}$. Results of the physiological parameters indicate that both glucose and lactate concentrations were also influenced by discharge. The outcomes from this study present important information about fish passage performance across low-head ramped weirs and could provide data needed to help biologists and engineers to develop more effective structures to alleviate small instream obstacles.
\end{abstract}

Keywords: low-head ramped weirs; substrate addition; potamodromous cyprinid species; upstream migration; physiological parameters; ecohydraulics

\section{Introduction}

River fragmentation stands out as one of the most important pressures in European rivers and streams, with potentially more than 1.2 million instream barriers [1,2]. Of these, $68 \%$ are low-head structures (i.e., structures less than two metres in height), which are often unreported. The cumulative impact that these small obstacles have on river connectivity may be, therefore, greater than estimated, and far more harmful than that of large obstacles, due to their high abundance in rivers worldwide [1-4].

Low-head weirs are one of the most common small-engineered structures and are considered a pressure on the sustainability of fish populations [5-8], by blocking fish movements to reach important reproduction, feeding and refuge habitats [9-11]. In Portuguese rivers, more than 8000 small weirs ( $<5 \mathrm{~m}$ high) have been reported [12], with low-head ramped weirs being one of the most common designs [13]. As in most European countries, many of these small weirs were built at the turn of the Eighteenth Century or 
earlier and have nowadays ceased to perform the function for which they were implemented, being obsolete or non-operational [14]. Thus, according to the European Water Framework Directive guidelines (WFD; [15]), field assessment is conducted to determine the possible removal of the barrier, which is in compliance with the new EU Biodiversity Strategy target of reconnecting at least 25,000 km of rivers in Europe by 2030 (Document 52020DC0380; [16]). However, when such removal is not possible, due to social, economic and/or historical significance, requalification measures are implemented to enhance fish passability, such as the addition of a natural substrate to the ramp (referred to as retrofitting) to mimic natural stream conditions and promote energy dissipation [17-21]. Despite some studies highlighting the usefulness of retrofitting for aiding fish passage through technical fishways [22,23], few studies are available on how this measure affects the negotiation of low-head ramped weirs, particularly by potamodromous cyprinid species, which are an important component of European fish assemblages [24-26].

The permeability of low-head ramped weirs to fish movements should be considered site-, season- and species-specific $[19,21,27]$. The effect that these instream obstacles have on fish migratory movements may not be linearly related to the number of small weirs that fish need to negotiate, but closely dependent on the physical characteristics of the weirs (e.g., ramp length, slope, substrate on ramp), on the hydrodynamic conditions present in the vicinity of the structure (i.e., velocity magnitude and turbulence, which are closely related to discharge), and on fish swimming abilities $[19,28,29]$, which are directly associated with fish species' eco-morphological characteristics and individual body size [30-32]. In addition, along with these key physical and hydraulic parameters, physiological conditions of fish, such as stress level and fatigue, should also be considered when assessing fish passage performance [33,34]. Measurements of physiological parameters, such as glucose and lactate concentrations in blood samples, using portable point-of-care devices [35], are frequently applied to assess exercise effort and fish physiological responses to stress [33-37]. However, most studies are mainly focused on salmonids, as well as other game fish species such as largemouth bass or pike [35,38,39], and less is known about physiological responses for potamodromous cyprinids.

The present study aimed to assess the performance of an experimental low-head ramped weir to enhance the passage of a cyprinid species, the Iberian barbel (Luciobarbus bocagei (Steindachner, 1864)), a representative of medium-sized benthic potamodromous cyprinids commonly present in Iberian and Western European rivers [23,34], which performs significant migratory movements, mainly for reproductive purposes, and is particularly susceptible to river fragmentation $[13,40]$. Special attention was given to testing the effects of retrofitting designs (RD), considering the addition of a natural substrate, such as cobbles randomly embedded on the ramp (two scenarios: Control (smooth bottom, with no substrate) vs. Nature (cobbles added)), and discharge (Q; $55 \mathrm{~L} \cdot \mathrm{s}^{-1}$ and $110 \mathrm{~L} \cdot \mathrm{s}^{-1}$ (or specific discharge per unit width, $\mathrm{q} ; 92 \mathrm{~L} \cdot \mathrm{s}^{-1} \cdot \mathrm{m}^{-1}$ and $\left.183 \mathrm{~L} \cdot \mathrm{s}^{-1} \cdot \mathrm{m}^{-1}\right)$ ) on fish passage performance. Though a similar study has been performed on the same species [41], the present one used individual fish rather than schools to avoid confounding effects from schooling behaviour, allowing us to analyse the data using characteristics of individuals and to exclude potential effects of the presence of other fish [42]. Additionally, fish physiological responses to stress and fatigue, measured by glucose (GLUC; $\mathrm{mg} \cdot \mathrm{dL}^{-1}$ ) and lactate (LACT; mmol $\cdot \mathrm{L}^{-1}$ ) concentrations in blood samples, respectively, were also analysed for all tested fish. The conditions tested are representative of those that fish are expected to overcome during their upstream migration in Iberian small watercourses [13]. It was expected that: (i) the passage performance of fish, considering the attraction as well as upstream successful passages and time taken to the complete negotiation, would be influenced by both factors RD and $\mathrm{Q}$, and that (ii) physiological responses to stress and fish fatigue would increase with increasing $Q$ and, consequently, with configurations presenting high turbulence and high velocity magnitude. 


\section{Materials and Methods}

\subsection{Experimental Facility}

Experiments were conducted in an indoor ecohydraulic flume installed at the Hydraulics and Environment Department of the National Laboratory for Civil Engineering (LNEC), in Lisbon. The flume (Figure 1A) consists of a steel frame, $10.00 \mathrm{~m}$ long $\times 0.60 \mathrm{~m}$ wide $\times 1.20 \mathrm{~m}$ high, with an upstream and a downstream tank separated from the main channel by mesh panels, from where the water enters the flume and is recirculated. The sidewalls of the main channel are glass-viewing panels, to allow a direct observation of fish behaviour throughout the experiments. As in previous studies [43,44], the channel was set at a $3 \%$ slope, in order to represent the average slope of central and southern Iberian small size watercourses (Catchment Characterisation and Modelling, version 2 (CCM2); [45]).

A)
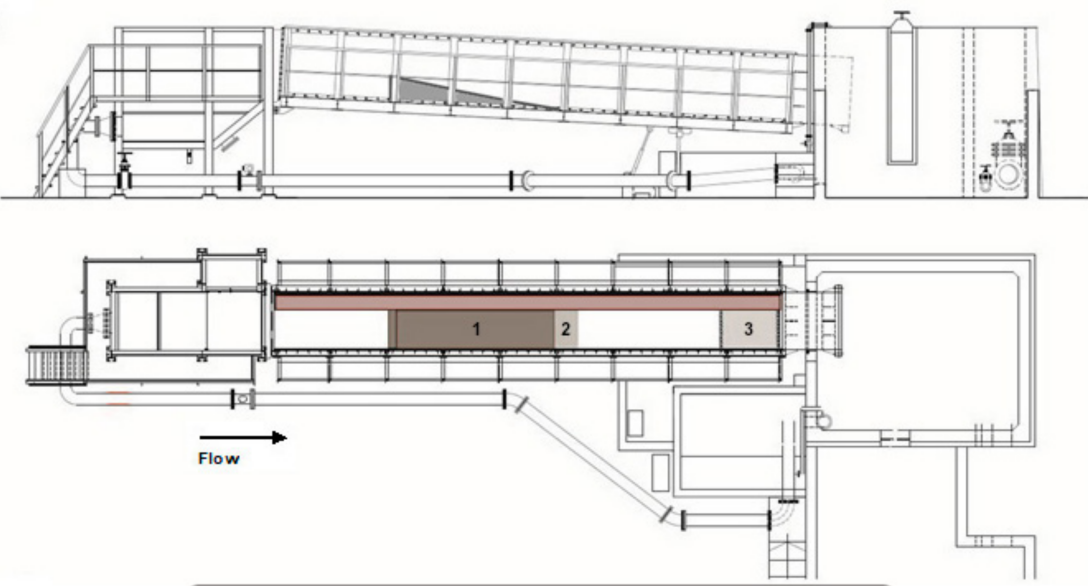

B)

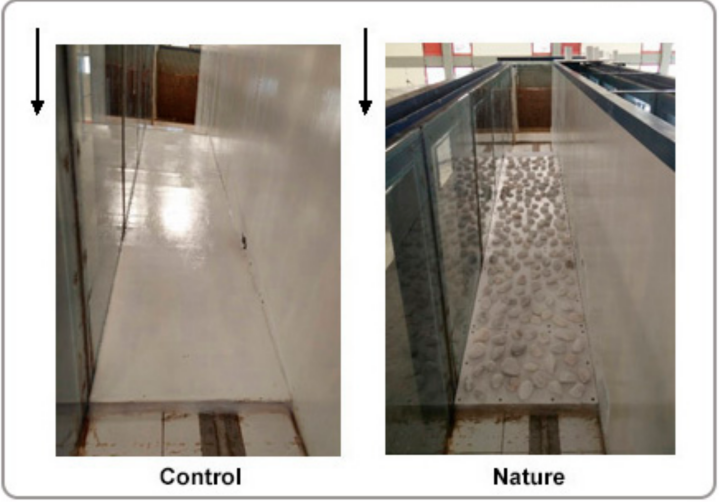

Figure 1. (A) Scheme of the experimental flume, representing a side view of the channel on a slope of $3 \%$ (above), and a top view (below) with the location of (1) the experimental low-head ramped weir (ramp $3.00 \mathrm{~m}$ long on a slope of $10 \%$, with a $0.20 \mathrm{~m}$ wide weir crest, located $2.50 \mathrm{~m}$ upstream of the acclimation area), (2) the approach area (the $0.30 \mathrm{~m}^{2}$ shaded area immediately downstream of the ramp toe), and (3) the acclimation area (the $0.60 \mathrm{~m}^{2}$ shaded area between the two removable fine mesh panels located downstream). (B) Images of the configurations tested, contemplating the Control ramp (without substrate) and the retrofitted Nature design (ramp with cobbles of 10 to $30 \mathrm{~cm}$, randomly distributed).

An experimental low-head ramped weir made of maritime plywood, with a length of $3.00 \mathrm{~m}$ and a slope of $10 \%$, was fixed in the flume (Figure 1A) at $2.50 \mathrm{~m}$ upstream of the acclimation area, a $0.60 \mathrm{~m}^{2}$ area created by two mesh panels in the downstream zone of the flume. A $0.50 \mathrm{~m}$ long approach zone was established immediately downstream of the ramp toe. To test the effect of RD on fish passage performance, two different configurations (Figure 1B), selected based on the results of a previous study by Amaral et al. [41], were tested, encompassing: (i) a Control ramp, smooth bottom without substrate, 
and (ii) a retrofitted scenario (Nature), with cobbles of 0.10 to $0.30 \mathrm{~m}$ randomly embedded on the ramp, which was found to be the most suitable retrofitting design to enhance the negotiation of these barriers by potamodromous cyprinids. To assess the influence of $Q$ on fish passage performance, both configurations were tested under two discharges: 55 and $110 \mathrm{~L} \cdot \mathrm{s}^{-1}$. Discharge was measured by a flow meter installed in the supply pipe. Hydrodynamics of the tested configurations were previously characterized by numerical modelling (detailed characterization can be consulted in Amaral et al. [41]). Water depths observed at the sloping face during the Control scenario $(6$ and $10 \mathrm{~cm}$, for $\mathrm{Q}=55$ and $110 \mathrm{~L} \cdot \mathrm{s}^{-1}$, respectively) were shallower than in the Nature configuration (9 and $13 \mathrm{~cm}$, for $\mathrm{Q}=55$ and $110 \mathrm{~L} \cdot \mathrm{s}^{-1}$, respectively). In terms of mean flow velocity, higher magnitudes were registered in the Control scenario, especially with $110 \mathrm{~L} \cdot \mathrm{s}^{-1}$ (max mean magnitude of 2.6 and $3.4 \mathrm{~m} \cdot \mathrm{s}^{-1}$, for $\mathrm{Q}=55$ and $110 \mathrm{~L} \cdot \mathrm{s}^{-1}$, respectively), compared with the Nature configuration (max mean magnitude of 2.5 and $2.7 \mathrm{~m} \cdot \mathrm{s}^{-1}$, for $\mathrm{Q}=55$ and $110 \mathrm{~L} \cdot \mathrm{s}^{-1}$, respectively). Values of turbulent kinetic energy per unit mass were also higher in the Control scenario, for both $Q$ tested, registering intensities of nearly $0.30 \mathrm{~m}^{2} \cdot \mathrm{s}^{-2}$ at the ramp toe; for the Nature configuration, turbulence intensity was around $0.25 \mathrm{~m}^{2} \cdot \mathrm{s}^{-2}$.

\subsection{Fish Experiments}

A total of 80 Iberian barbels, selecting only adult fish to avoid bias in swimming performance, were used in the experiments (mean total length (TL) \pm standard deviation $(\mathrm{SD})=19.3 \pm 2 \mathrm{~cm}$; mean body mass $(\mathrm{M}) \pm \mathrm{SD}=65.8 \pm 24.5 \mathrm{~g})$. Fish were captured by wadable electrofishing (Hans Grassl IG-200) in the Lisandro River, a small Atlantic coastal river near Lisbon. A total of four electrofishing samplings were performed (one sampling per week, collecting 20 fish per episode) according to the protocol adopted by the European Committee for Standardization [46]. Fish were transported, in a fish transporter box (Hans Grassl, $190 \mathrm{~L}$ ) with external aeration, to the laboratory facilities at LNEC, and were maintained for a maximum period of 6 days in filtered and aerated acclimation tanks (700 L tanks; Fluval Canister Filter FX5). Water quality of the tanks was monitored daily (temperature $=23 \pm 1{ }^{\circ} \mathrm{C}, \mathrm{pH}=7.7 \pm 0.2$, and conductivity $=194 \pm 19 \mu \mathrm{s} \cdot \mathrm{cm}^{-1}$ ), using a multiparametric probe (HANNA, HI 9812-5), and high-quality levels (i.e., active fish, no mortality) were ensured by the mechanical and biological filtration system, with a turnover rate of $2300 \mathrm{~L} \cdot \mathrm{h}^{-1}$. Fish were only tested after a 48 -h period of acclimation to the holding conditions in the laboratory.

Experiments were performed during late spring-early summer, described as the main reproductive season for this species [47,48], always in the morning period (07.00-14.00), so that environmental conditions, such as temperature and light, were fairly constant throughout the experiments. Each combination of RD and Q was replicated 20 times using individual fish, randomly selected from the acclimation tanks, and each fish was used only once. Each replicate started with an acclimation period of $15 \mathrm{~min}$, for the fish to adapt to the flume flow conditions, and lasted until the successful negotiation of the ramp, or for a maximum of $60 \mathrm{~min}$. Fish movements, such as the number of times fish entered the approach area (AP); the number of times fish entered into the ramp and actively tried to negotiate it (AT); the negotiation of the entire ramp, reaching the upstream part of the flume-complete successful passages (S); and the time taken to achieve the successful upstream passage- transit time (T), were monitored by direct observation and recorded (top view) by a video camera (GoPro HERO5). Metrics of passage performance, such as percentage of attraction efficiency $(\mathrm{AE} \%=\mathrm{AT} / \mathrm{AP} \times 100)$, percentage of passage efficiency $(\mathrm{PE} \%=\mathrm{S} / \mathrm{AT} \times 100)$ and success rate $(\mathrm{SR} \%=\mathrm{S} / \mathrm{n} \times 100)$, were then calculated. At the end of each trial, to assess physiological responses to stress and fish fatigue of all tested fish, blood glucose (GLUC; $\mathrm{mg} \cdot \mathrm{dL}^{-1}$ ) and lactate $\left(\mathrm{LACT} ; \mathrm{mmol} \cdot \mathrm{L}^{-1}\right.$ ) concentrations were measured using the portable meters Accucheck Aviva (Roche) and Lactate Plus (Nova Biomedical UK), respectively. The methodology applied was the same as in other studies of fish behaviour and passage performance conducted in ecohydraulic flumes $[33,34,37]$. The tested fish was restrained in a V-shaped padded bed, where fresh water was continuously 
provided, and a blood sample (0.1-0.5 $\mathrm{mL}$ ) was collected from the caudal vasculature, using a $23 \mathrm{G}$ or $25 \mathrm{G}$ preheparinized needle. The procedure to collect the blood and insert it into the slot of each reader was conducted in less than $1 \mathrm{~min}$. After this procedure, the fish was measured ( $\mathrm{TL} \pm 0.1 \mathrm{~cm})$ and weighed $(\mathrm{M} \pm 0.1 \mathrm{~g})$, and water quality in the flume was monitored (temperature $=23 \pm 1{ }^{\circ} \mathrm{C}, \mathrm{pH}=7.9 \pm 0.2$, and conductivity $=181 \pm 19 \mu \mathrm{s} \cdot \mathrm{cm}^{-1}$ ).

The study was conducted in strict accordance with ethical provisions on the welfare of experimental animals enforced by the European Union and was coordinated by J.M. Santos, who holds a FELASA level C certification (www.felasa.eu) to direct animal experiments. Fish experiments and maintenance in the laboratory and experimental facility were authorized (reference DGAV: 0420/000/000/2012) by the Department for Health and Animal Protection (Direcção de Serviços de Saúde e Protecção Animal) in accordance with the recommendations of the "Protection of animals use for experimental and scientific work". Fishing and handling permits for the capture of wild fish (96/2018/CAPT, 97/2018/CAPT and 98/2018/CAPT) were issued by the Portuguese Institute for Nature Conservation and Forests (ICNF, I.P.). No fish were sacrificed during the experiments, and efforts were made to minimize stress.

\subsection{Data Analysis}

To identify differences between replicates in fish movements (AP, AT, $\mathrm{S}$ and $\mathrm{T}$ ), as well as physiological responses (LACT and GLUC concentrations), a non-parametric KruskalWallis $\mathrm{H}$ test was performed, using the dunn.test package [49], from the open-source software R [50].

Additionally, to analyse the influence of factors RD (Control (no substrate) vs. Nature (cobbles added)), and $\mathrm{Q}\left(55 \mathrm{~L} \cdot \mathrm{s}^{-1}\right.$ and $\left.110 \mathrm{~L} \cdot \mathrm{s}^{-1}\right)$, as well as their interaction, on the passage performance and physiological response of Iberian barbels-considering the movements of AP and AT (AP \& AT), S, T, as well as blood LACT and GLUC - a PERMANOVA test applying the Euclidean distance was performed, using the package PERMANOVA for PRIMER $+v 6.0$ [51]. This statistical test was selected for being a robust non-parametric method based on permutations tests that directly partitions the variation in a distance matrix according to Euclidean distances or non-Euclidean-embeddable dissimilarity measures [52,53]. In this analysis, the Euclidean distance was applied to compute the distance matrix due to the presence, and relevance, of zeros in the assessed data [51].

\section{Results}

The total number of times fish approached the ramped weir or attempted to negotiate it, and the total successful passages, as well as the time taken to completely negotiate the ramp varied significantly among configurations (Kruskal-Wallis H test; AP: $\mathrm{H}=49.761$, 3 d.f., $P=8.984 \times 10^{-11}$; AT: $\mathrm{H}=56.051$, 3 d.f., $P=4.098 \times 10^{-12}$; S: $\mathrm{H}=23.165,3$ d.f., $P=3.730 \times 10^{-05} ; \mathrm{T}: \mathrm{H}=19.570,3$ d.f., $\left.P=0.0002\right)$, as presented in Table 1 . Results showed that the total number of AP, AT and $\mathrm{S}$ were higher in the Nature configuration when compared with the Control scenario, except for the total number of AP registered under $\mathrm{Q}=55 \mathrm{~L} \cdot \mathrm{s}^{-1}$ ( $\mathrm{AP}=208$ and 572, for Nature and Control, respectively). Regarding the effect of $\mathrm{Q}$ on fish movements, the total number of $\mathrm{AP}$ and $\mathrm{AT}$, as well as $\mathrm{S}$, decreased notably with increasing $Q$. For the Control scenario, reductions of $98 \%, 97 \%$ and $79 \%$ were registered, considering the AP, AT and S movements, respectively. As for the Nature configuration, smaller reductions were recorded, counting 77\%, 94\% and 53\% fewer AP, AT and $\mathrm{S}$ movements, respectively. Regarding the metrics of passage performance, although $\mathrm{Q}=55 \mathrm{~L} \cdot \mathrm{s}^{-1}$ recorded an overall high number of fish movements, values of $\mathrm{AE} \%$ and $\mathrm{PE} \%$ were lower than those registered with $\mathrm{Q}=110 \mathrm{~L} \cdot \mathrm{s}^{-1}$, except for $\mathrm{AE} \%$ registered in the Nature configuration $\left(229 \%\right.$, with $\left.\mathrm{Q}=55 \mathrm{~L} \cdot \mathrm{s}^{-1}\right)$. As for $\mathrm{SR} \%$, higher success rates were recorded in the Nature configuration, registering an increase of $18 \%$ for $Q=55 \mathrm{~L} \cdot \mathrm{s}^{-1}$, and $43 \%$ for $Q=110 \mathrm{~L} \cdot \mathrm{s}^{-1}$, when compared with the Control scenario. In terms of time taken by fish to completely negotiate the ramped weir, for $Q=55 \mathrm{~L} \cdot \mathrm{s}^{-1}$, faster negotiations were recorded, on average, in the Control scenario (19 $\pm 15 \mathrm{~min}$ vs. $26 \pm 18 \mathrm{~min}$, for the 
Control and the Nature configurations, respectively); however, for $\mathrm{Q}=110 \mathrm{~L} \cdot \mathrm{s}^{-1}$, faster negotiations were registered in the Nature configuration ( $19 \pm 15 \mathrm{~min}$ vs. $32 \pm 18 \mathrm{~min}$, for the Nature and the Control configurations, respectively). Results of the PERMANOVA analysis (Table 2) indicated that the number of AP and AT (AP \& AT) was significantly influenced by factors $\mathrm{RD}$ and $\mathrm{Q}$, as well as by the combination of $\mathrm{RD} \times \mathrm{Q}$. Concerning the influence on $\mathrm{S}$, results reveal that successful negotiation was significantly influenced by $R D$ and by $Q$, but their interaction $(R D \times Q)$ was not significant $(p<0.05)$. As for $T$, time taken by fish to successfully negotiate the ramp was only significantly influenced by $Q$.

Table 1. Results for the tested configurations contemplating the Control and Nature retrofitting designs (RD), run under two discharges (Q), 55 and $110 \mathrm{~L} \cdot \mathrm{s}^{-1}$. Total number of fish tested (N), total number of approaches (AP), total number of attempts (AT), number of fish that approached and made attempts (n), total of upstream successful passages (S), percentage of attraction efficiency (AE\%; ratio of $\mathrm{AT} / \mathrm{AP} \times 100)$, percentage of passage efficiency $(\mathrm{PE} \%$; ratio of $\mathrm{S} / \mathrm{AT} \times 100)$, success rate $(\mathrm{SR} \%$; ratio of $\mathrm{S} / \mathrm{n} \times 100)$ and mean transit time (mean \pm standard deviation; $\overline{\mathrm{T}}( \pm \mathrm{SD})$ ).

\begin{tabular}{ccccccccccc}
\hline RD & $\mathbf{Q}$ & $\mathbf{N}$ & $\mathbf{A P}$ & $\mathbf{A T}$ & $\mathbf{n}$ & $\mathbf{S}$ & $\mathbf{A E} \%$ & $\mathbf{P E} \%$ & $\mathbf{S R} \%$ & $\overline{\mathbf{T}}( \pm \mathbf{S D})$ \\
\hline \multirow{2}{*}{ CONTROL } & 55 & 20 & 572 & 317 & 20 & 14 & 55 & 4 & 70 & $19( \pm 15)$ \\
& 110 & 20 & 11 & 8 & 8 & 3 & 73 & 38 & 38 & $32( \pm 18)$ \\
\hline \multirow{2}{*}{ NATURE } & 55 & 20 & 208 & 476 & 20 & 17 & 229 & 4 & 85 & $26( \pm 18)$ \\
& 110 & 20 & 47 & 27 & 12 & 8 & 57 & 30 & 67 & $19( \pm 15)$ \\
\hline
\end{tabular}

Table 2. Results of the main PERMANOVA test, regarding the number of approaches and attempts (AP \& AT), successful passages (S) and transit time (T; min), as well as concentrations of lactate (LACT; mmol. $\mathrm{L}^{-1}$ ) and glucose (GLUC; $\mathrm{mg} \cdot \mathrm{dL}^{-1}$ ) in blood samples according to the retrofitting designs (RD) and discharges $(\mathrm{Q})$ tested. Bold values highlight significant differences, considering $p \leq 0.05$; italics show marginally significant influence, considering $0.05<p \leq 0.10$.

\begin{tabular}{ccccccc}
\hline Factors & & AP \& AT & S & T & LACT & GLUC \\
\hline RD & F: & 3.412 & 4.312 & 1.769 & 0.514 & 0.118 \\
& P: & $\mathbf{0 . 0 4 7}$ & $\mathbf{0 . 0 4 1}$ & 0.206 & 0.489 & 0.759 \\
$\mathbf{Q}$ & F: & 26.848 & 26.950 & 16.540 & 4.441 & 3.196 \\
& P: & $\mathbf{0 . 0 0 1}$ & $\mathbf{0 . 0 0 1}$ & $\mathbf{0 . 0 0 1}$ & $\mathbf{0 . 0 4 4}$ & $\mathbf{0 . 0 8 2}$ \\
$\mathbf{R D} \times \mathbf{Q}$ & F: & 4.400 & 0.269 & 1.712 & 0.062 & 1.036 \\
& P: & $\mathbf{0 . 0 2 1}$ & 0.626 & 0.203 & 0.821 & 0.337 \\
\hline Res & & 76 & 76 & 76 & 76 & 76 \\
Total & & 79 & 79 & 79 & 79 & 79 \\
\hline
\end{tabular}

Regarding the concentrations of physiological parameters LACT and GLUC in blood (Figure 2), results from the Kruskal-Wallis $\mathrm{H}$ test indicated no significant differences among tested configurations (LACT: $\mathrm{H}=46.291$, 48 d.f., $P=0.543$; GLUC: $\mathrm{H}=23.224$, 41 d.f., $P=0.989)$, nor between fish that successfully negotiated the ramped weir and those that were unsuccessful (LACT: $\mathrm{H}=44.711$, 43 d.f., $P=0.399$; GLUC: $\mathrm{H}=30.210$, 35 d.f., $P=0.699$ ). However, it is possible to identify a tendency of increasing concentration values of LACT (Figure 2A) in trials run with $\mathrm{Q}=55 \mathrm{~L} \cdot \mathrm{s}^{-1}$ when compared with $110 \mathrm{~L} \cdot \mathrm{s}^{-1}$, from 3.5 to $4.6 \mathrm{mmol} \cdot \mathrm{L}^{-1}$ for the Control scenario, and from 4 to $4.8 \mathrm{mmol} \cdot \mathrm{L}^{-1}$ for the Nature configuration (median values). On the other hand, for GLUC (Figure 2B), increasing values were registered in trials with $Q=110 \mathrm{~L} \cdot \mathrm{s}^{-1}$, from 57 to $60.5 \mathrm{mg} \cdot \mathrm{dL}^{-1}$, and from 57 to $60 \mathrm{mg} \cdot \mathrm{dL}^{-1}$ (median values), for the Control and Nature configurations, respectively. Results of the PERMANOVA analysis (Table 2) corroborate this tendency for $Q$, indicating that $Q$ significantly influenced LACT concentrations, registering a decrease with increasing $\mathrm{Q}$, as mentioned before, but for GLUC concentrations, results suggest only a marginally significant influence (i.e., $P \leq 0.10$ ) of $Q$, with an increase in blood GLUC occurring with increasing $Q$. 

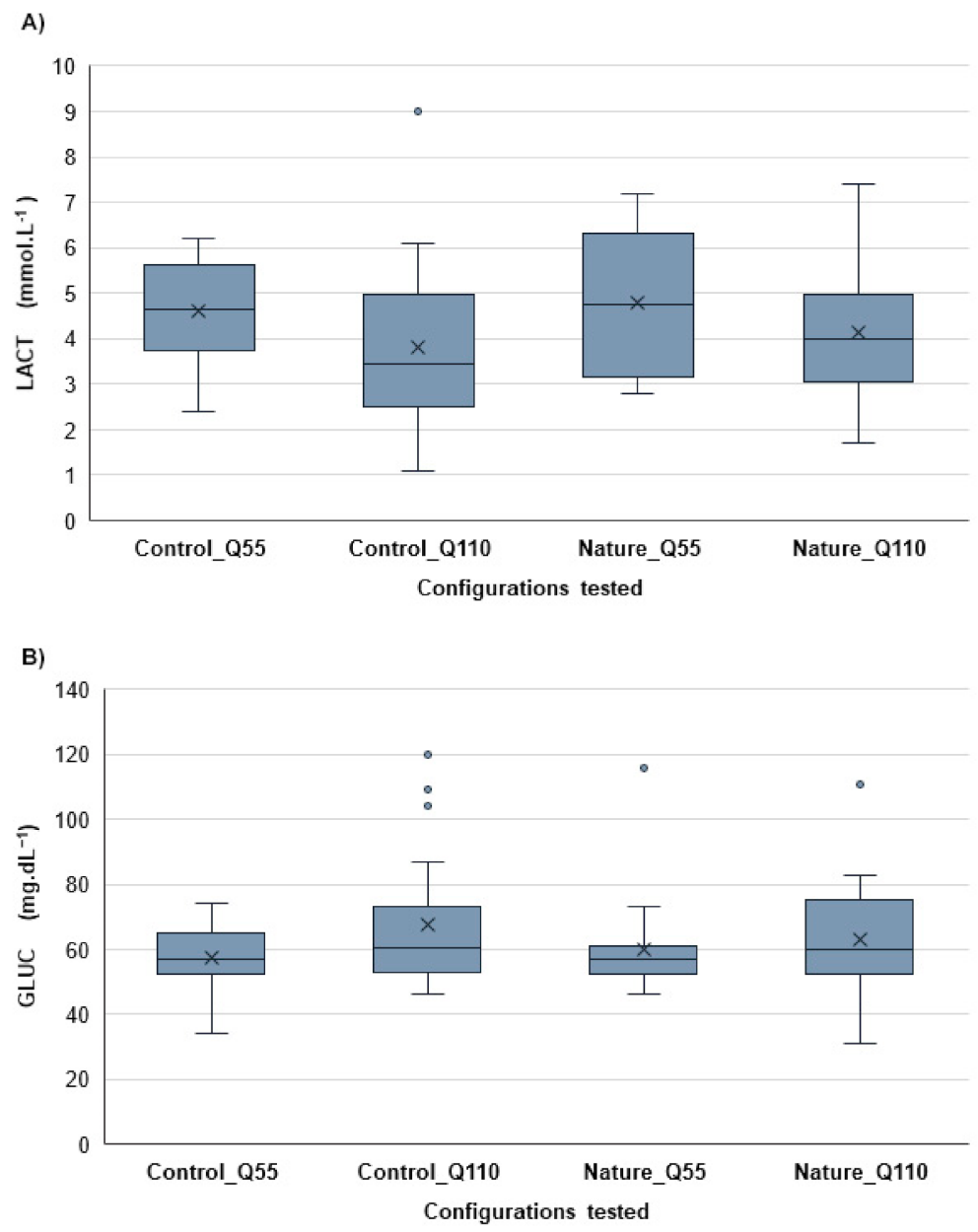

Figure 2. Boxplots of the variation in fish physiological responses to stress and fatigue, measured by (A) lactate (LACT; mmol. $\mathrm{L}^{-1}$ ) and (B) glucose (GLUC; $\mathrm{mg} \cdot \mathrm{dL}^{-1}$ ) concentrations in blood samples, respectively. Crosses correspond to the mean value of the physiological response for each treatment; inner lines represent the median value. Box and whiskers correspond to quartile dispersion. Points represent outliers.

\section{Discussion}

The present study aimed to assess the performance (measured by the number of approaches to the ramp, attempts to negotiate it, successful upstream passages and transit time), and fish physiological response to stress and fatigue, of a widespread cyprinid species (the Iberian barbel) facing an experimental low-head ramped weir retrofitted by the placement of cobbles and subjected to different discharges. The use of individual fish rather than schools, as previously tested by Amaral et al. (e.g., [41,43]), allowed the analysis of data using characteristics of individuals, as well as the exclusion of potential effects of the presence of other fish and of schooling behaviours [42]. Fish behaviour and movements observed during the experiments (approaches, attempts and successful upstream passages) show that Iberian barbels were stimulated to move upstream. However, the number of times fish approached the ramped weir, or attempted to negotiate it, the total successful passages, and the time taken to completely negotiate the ramp, as well as the physiological responses to stress and fatigue varied among configurations tested, indicating that RD and $\mathrm{Q}$ are key factors driving fish passage performance.

The addition of a natural substrate to the sloping face of the ramped weir (Nature design) proved to be an effective retrofitting measure for higher discharges, generally increasing fish movements, successful upstream passages (SR\% increased by $43 \%$ ), and overall, enhancing fish passage performance by enabling faster negotiations of the obstacle. 
The random placement of natural cobbles generated an effective energy dissipation, as showed in Amaral et al. [41], reducing flow velocity magnitude along the ramp, particularly for $\mathrm{Q}=110 \mathrm{~L} \cdot \mathrm{s}^{-1}$ (from $3.4 \mathrm{~m} \cdot \mathrm{s}^{-1}$, registered in the Control scenario, to $2.7 \mathrm{~m} \cdot \mathrm{s}^{-1}$, in the Nature configuration), and especially turbulence registered downstream (from $<0.3 \mathrm{~m}^{2} \cdot \mathrm{s}^{-2}$ to $<0.25 \mathrm{~m}^{2} \cdot \mathrm{s}^{-2}$, in the Control and Nature configurations, respectively), therefore creating more favourable hydrodynamic conditions for fish to approach the ramped weir and attempt to successfully negotiate it (for more details on hydrodynamics, consult Amaral et al. [41], where a complete description of the hydrodynamic scenarios modelled and tested can be found). However, for the lower discharge, $55 \mathrm{~L} \cdot \mathrm{s}^{-1}$, faster negotiations occurred in the Control scenario, most likely due to the attractive and clear path formed along the ramp, in addition to suitable velocity magnitudes $\left(\approx 2.6 \mathrm{~m} \cdot \mathrm{s}^{-1}\right)$. Likewise, discharge $(Q)$ also proved to be an important variable for fish passage performance, as observed in other studies by Amaral et al. [41,44], Muraoka et al. [54] and Plesiński et al. [55]. In the present study, fish movements were notably affected by $\mathrm{Q}$ increase, for both tested configurations, registering significant reductions in AP and AT movements, as well as $\mathrm{S}$. This reduction in movements could indicate that, with high $Q$, velocity magnitudes and turbulence occurring close to the ramps, combined with the notable presence of hydraulic jumps, which are parameters directly related to $Q[19,20]$ that can assume higher magnitudes in the field than those experienced in these trials, may hamper fish movements and consequently the successful negotiations of these structures. In addition, $Q$ also significantly influenced the time taken by fish to completely negotiate the ramped weir, as envisaged initially. With the increase in $\mathrm{Q}$ in the Control configuration, fish took longer to approach the ramp and to attempt to negotiate it, and finally, to successfully overcome it, recording mean transit times of $19( \pm 15) \mathrm{min}$, for $55 \mathrm{~L} \cdot \mathrm{s}^{-1}$, and longer times of $32( \pm 18) \mathrm{min}$, for $110 \mathrm{~L} \cdot \mathrm{s}^{-1}$. However, for the Nature design, unlike the Control configuration, fish took less time to approach the ramp and successfully negotiate it with increasing $Q$, registering mean transit times of $19( \pm 15) \mathrm{min}$, in this case for $110 \mathrm{~L} \cdot \mathrm{s}^{-1}$, and longer times of $26( \pm 18) \mathrm{min}$, for $55 \mathrm{~L} \cdot \mathrm{s}^{-1}$. Once more, this result highlights the importance that retrofitting low-head ramped weirs, especially by adding a natural substrate, such as cobbles, may have on the passage performance of fish, by promoting an effective energy dissipation along the ramp and immediately downstream of the weir. Moreover, with high discharges, the placement of cobbles, randomly distributed along the ramp, may provide important "flow refugia" [56], by creating areas and paths of reduced velocity and less turbulence that may be used by fish during the upstream negotiation of the ramp [21,57], especially when substrate dimensions are similar or larger than the body size of fish.

Regarding the physiological parameters assessed in blood samples taken at the end of each trial, results revealed that concentrations of GLUC, generally associated with responses to stress $[33,36,37,58]$, and especially of LACT, used as a proxy to characterize fish effort and fatigue $[33,34,37]$, were only influenced by Q. As initially expected, and in line with the study by Costa et al. [33] on hydropeaking events, blood GLUC increased with increasing $Q$, suggesting that increasing velocity magnitudes and turbulence experienced by fish may have triggered a stress response, conditioning a series of primary defence mechanisms associated with endocrine processes, and a consequent increase in glucose production $[36,39,59]$. That increase in GLUC could have been higher if trials were longer and/or higher $Q$ were tested, as suggested by White et al. [39] — as the fish exposure to stress continues, more glucose is produced. Concerning LACT concentrations, although an increase in LACT with increasing $Q$ was initially expected, due to higher velocity magnitudes and turbulence that fish needed to overcome, thus implying greater effort, the opposite was observed. Higher concentrations of LACT were registered with the lower $Q$, of $55 \mathrm{~L} \cdot \mathrm{s}^{-1}$. These results may be related to the numerous fish movements registered with that $\mathrm{Q}$, especially the high number of AP and AT movements, and consequent burst speeds [60], compared with the number of movements recorded with $110 \mathrm{~L} \cdot \mathrm{s}^{-1}$ (generally, more than 10 times inferior). Therefore, as was also observed by White et al. [39] in experiments to assess the effects of different air exposures and exercise durations on behaviour and 
physiological parameters of two black bass species, largemouth bass (Micropterus salmoides) and smallmouth bass (Micropterus dolomieu), the concentrations of LACT in blood increased as a consequence of the intensive exercise of fish. During these experiments, which can be exhaustive, high-intensity anaerobic exercise that extensively uses white muscle is naturally experienced, inducing a variety of physiological responses closely related to lactate production and accumulation, as an anaerobic metabolic end-product [39,61].

To establish more applicable designs and retrofitting guidelines for these low-head barriers, it is crucial to implement a holistic approach that facilitates the upstream passage of fish by promoting hydrodynamic conditions suitable for an effective and efficient passage, considering all the fish movements/behaviours (approach to the structure, attempt to negotiate it, successful passage, transit time), and also the physiological responses of fish (stress, negotiation effort) throughout those conditions. Results from this study, which should be considered and analysed as a pilot study, may indicate trends in fish behaviour, providing valuable information about which critical variables to consider when designing low-head weirs and retrofitting solutions. Nevertheless, further research on fish passage performance and hydrodynamics of low-head ramped weirs should be carried out, in the laboratory and in the field, throughout the seasons, encompassing different retrofitting designs (e.g., diverse substrates and roughness, size and spatial arrangement), distinct fish species with different ecological traits (e.g., small-bodied fish that utilize the upper portion of the water column), and different size classes and life-cycle stages.

\section{Conclusions}

This study has highlighted the importance of the addition of a natural substrate, such as cobbles, and discharge for the passage performance and physiological responses to stress and fatigue (measured by blood glucose and lactate concentrations, respectively) of the Iberian barbel, a medium-sized potamodromous cyprinid, when negotiating a low-head ramped weir. Results showed that, for higher discharges, the addition of cobbles randomly distributed on the ramp (Nature design) generally increased fish movements and successful upstream passages, and overall enhanced fish passage performance by enabling faster negotiations of the obstacle. With increasing discharge, fish movements were notably affected in both configurations tested (Control and Nature). Additionally, time taken by fish to negotiate the ramped weir in the Control configuration increased with increasing discharge, but, with the same increase, in the Nature design fish took less time to approach the ramp and successfully negotiate it, highlighting the importance that retrofitting lowhead ramped weirs has on effective energy dissipation. As initially expected, blood glucose increased with increasing discharge, suggesting that increasing velocity magnitudes and turbulence experienced by fish may have triggered a stress response. However, for lactate concentrations, contrary to what was expected, higher values were registered with the lower discharge, possibly due to the numerous fish movements registered with $55 \mathrm{~L} \cdot \mathrm{s}^{-1}$. The outcomes from this study, complemented by further research on the hydrodynamics of low-head ramped weirs and fish passage performance, may significantly contribute to helping engineers and biologists to design more appropriate passage structures for low-head instream obstacles.

Author Contributions: Conceptualization, S.D.A., P.B. and J.M.S.; methodology, S.D.A. and J.M.S.; formal analysis, S.D.A.; investigation, S.D.A., F.R., P.B. and J.M.S.; writing—original draft preparation, S.D.A. and J.M.S.; writing-review and editing, P.B., F.R., M.T.F. and A.N.P.; supervision, J.M.S. All authors have read and agreed to the published version of the manuscript.

Funding: Forest Research Centre (CEF) is a research unit funded by Fundação para a Ciência e a Tecnologia I.P. (FCT), Portugal (UIDB/00239/2020). Susana D. Amaral was funded by a PhD grant from University of Lisbon/Santander Totta (SantTotta/BD/RG2/SA/2011), and by FCT (SFRH/BD/110562/2015). Filipe Romão was funded by a grant from FCT for the PhD programme FLUVIO (PD/BD/52512/2014). Paulo Branco is financed by national funds via FCT, under "Norma Transitória - DL57/2016/CP1382/CT0020" and José M. Santos was supported by national funds via FCT under the "CEEC Institucional" 2018 programme (Ref. 2/ISA/FCT/2018). 
Institutional Review Board Statement: The study was conducted according to the guidelines on experimental ethical provisions and welfare of animals enforced by the European Union and was coordinated by J.M. Santos, who holds a FELASA level C certification (www.felasa.eu) to direct animal experiments. Fish experiments and maintenance in the laboratory and experimental facility were authorized (reference DGAV: 0420/000/000/2012) by the Department for Health and Animal Protection (Direcção de Serviços de Saúde e Protecção Animal) in accordance with the recommendations of the "Protection of animals use for experimental and scientific work". Fishing and handling permits for the capture of wild fish (96/2018/CAPT, 97/2018/CAPT, and 98/2018/CAPT) were issued by the Portuguese Institute for Nature Conservation and Forests (ICNF, I.P.).

Data Availability Statement: Not applicable.

Conflicts of Interest: The authors declare no conflict of interest.

\section{References}

1. $\quad$ Birnie-Gauvin, K.; Franklin, P.; Wilkes, M.; Aarestrup, K. Moving beyond fitting fish into equations: Progressing the fish passage debate in the Anthropocene. Aquatic Conserv. Mar. Freshw. Ecosyst. 2019, 29, 1095-1105. [CrossRef]

2. Belletti, B.; de Garcia Leaniz, C.; Jones, J.; Bizzi, S.; Börger, L.; Segura, G.; Castelletti, A.; van de Bund, W.; Aarestrup, K.; Barry, J.; et al. More than one million barriers fragment Europe's rivers. Nature 2020, 588, 436-441. [CrossRef]

3. Lucas, M.C.; Bubb, D.H.; Jang, M.-H.; Ha, K.; Masters, J.E.G. Availability of and access to critical habitats in regulated rivers: Effects of low-head barriers on threatened lampreys. Freshw. Biol. 2009, 54, 621-634. [CrossRef]

4. Birnie-Gauvin, K.; Aarestrup, K.; Riis, T.M.O.; Jepsen, N.; Koed, A. Shining a light on the loss of rheophilic fish habitat in lowland rivers as a forgotten consequence of barriers, and its implications for management. Aqua. Conserv. Mar. Freshw. Ecosyst. 2017, 27, 1345-1349. [CrossRef]

5. Ovidio, M.; Philippart, J.C. The impact of small physical obstacles on upstream movements of six species of fish-Synthesis of a 5-year telemetry study in the River Meuse basin. Hydrobiologia 2002, 483, 55-69. [CrossRef]

6. Calles, O.; Greenberg, L. Connectivity is a two-way street-The need for a holistic approach to fish passage problems in regulated rivers. River Res. Appl. 2009, 25, 1268-1286. [CrossRef]

7. Gozlan, R.E.; Karimov, B.K.; Zadereev, E.; Kuznetsova, D.; Brucet, S. Status, trends, and future dynamics of freshwater ecosystems in Europe and Central Asia. Inland Waters 2019, 9, 78-94. [CrossRef]

8. Reid, A.J.; Carlson, A.K.; Creed, I.F.; Eliason, E.J.; Gell, P.A.; Johnson, P.T.; Kidd, K.A.; MacCormack, T.J.; Olden, J.D.; Ormerod, S.J.; et al. Emerging threats and persistent conservation challenges for freshwater biodiversity. Biol. Rev. 2019, 94, 849-873. [CrossRef]

9. Aarts, B.G.; Van Den Brink, F.W.; Nienhuis, P.H. Habitat loss as the main cause of the slow recovery of fish faunas of regulated large rivers in Europe: The transversal floodplain gradient. River Res. Appl. 2003, 20, 3-23. [CrossRef]

10. Nilsson, C.; Reidy, C.A.; Dynesius, M.; Revenga, C. Fragmentation and flow regulation of the world's large river systems. Science 2005, 308, 405-408. [CrossRef] [PubMed]

11. King, S.; O'Hanley, J.R.; Newbold, L.R.; Kemp, P.S.; Diebel, M.W. A toolkit for optimizing fish passage barrier mitigation actions. J. Appl. Ecol. 2017, 54, 599-611. [CrossRef]

12. Ordeix, M.; González, G.; Sanz-Ronda, F.J.; Santos, J.M. Restoring fish migration in the rivers of the Iberian Peninsula. In From Sea to Source 2.0. Protection and Restoration of Fish Migration in Rivers Worldwide; Brink, K., Gough, P., Royte, J., Schollema, P.P., Wanningen, H., Eds.; World Fish Migration Foundation: Groningen, The Netherlands, 2018; pp. 174-179.

13. Branco, P.; Amaral, S.D.; Ferreira, M.T.; Santos, J.M. Do small barriers affect the movement of freshwater fish by increasing residency? Sci. Total Environ 2017, 581-582, 486-494. [CrossRef]

14. de Garcia Leaniz, C. Weir removal in salmonid streams: Implications, challenges and practicalities. Hydrobiologia 2008, 609, 83-96. [CrossRef]

15. 15. European Commission. Directive 2000/60/EC of the European Parliament and of the Council of 23 October 2000 establishing a framework for the community action in the field of water policy. Off. J. Eur. Comm. 2000, 327, 1-72.

16. European Commission. Bringing Nature Back into Our Lives. EU 2030 Biodiversity Strategy; Document 52020DC0380; 2020. Available online: https: / / eur-lex.europa.eu/legalcontent/EN/TXT/?qid=1590574123338\&uri=CELEX:52020 (accessed on 3 January 2021).

17. Food and Agriculture Organization (FAO)/DVWK. Fish Passes-Design, Dimensions and Monitoring; FAO: Rome, Italy, $2002 ;$ p. 119.

18. Baker, C.F. Effect of ramp length and slope on the efficacy of a baffled fish pass. J. Fish Biol. 2014, 84, 491-502. [CrossRef] [PubMed]

19. Baudoin, J.M.; Burgun, V.; Chanseau, M.; Larinier, M.; Ovidio, M.; Sremski, W.; Steinbach, P.; Voegtle, B. Assessing the Passage of Obstacles by Fish. Concepts, Design and Application; Onema: Paris, France, 2014; p. 200.

20. Towler, B.; Mulligan, K.; Haro, A. Derivation and application of the energy dissipation factor in the design of fishways. Ecol. Eng. 2015, 83, 208-217. [CrossRef]

21. Richer, E.E.; Fetherman, E.R.; Krone, E.A.; Wright, F.B.; Kondratieff, M.C. Multispecies Fish Passage Evaluation at a Rock-Ramp Fishway in a Colorado Transition Zone Stream. N. Am. J. Fish Manag. 2020, 40, 1510-1522. [CrossRef] 
22. Katopodis, C.; Aadland, L.P. Effective dam removal and river channel restoration approaches. Int. J. River Basin Manag. 2006, 4, 153-168. [CrossRef]

23. Santos, J.M.; Branco, P.; Katopodis, C.; Ferreira, T.; Pinheiro, A. Retrofitting pool-and-weir fishways to improve passage performance of benthic fishes: Effect of boulder density and fishway discharge. Ecol. Eng. 2014, 73, 335-344. [CrossRef]

24. Santos, J.M.; Reino, L.; Porto, M.; Oliveira, J.; Pinheiro, P.; Almeida, P.R.; Cortes, R.; Ferreira, M.T. Complex size-dependent habitat associations in potamodromous fish species. Aquat. Sci. 2011, 73, 233-245. [CrossRef]

25. Ferreira, T.; Oliveira, J.; Caiola, N.; De Sostoa, A.; Casals, F.; Cortes, R.; Economou, A.; Zogaris, S.; Garcia-Jalon, D.; Ilhéu, M.; et al. Ecological traits of fish assemblages from Mediterranean Europe and their responses to human disturbance. Fish. Manag. Ecol. 2007, 14, 473-481. [CrossRef]

26. Oliveira, J.M.; Segurado, P.; Santos, J.M.; Teixeira, A.; Ferreira, M.T.; Cortes, R.V. Modelling Stream-Fish Functional Traits in Reference Conditions: Regional and Local Environmental Correlates. PLoS ONE 2012, 7, e45787. [CrossRef]

27. Kelly-Richards, S.; Silber-Coats, N.; Crootof, A.; Tecklin, D.; Bauer, C. Governing the transition to renewable energy: A review of impacts and policy issues in the small hydropower boom. Energy Policy 2017, 101, 251-264. [CrossRef]

28. Solà, C.; Ordeix, M.; Pou-Rovira, Q.; Sellarès, N.; Queralt, A.; Bardina, M.; Casamitjana, A.; Munné, A. Longitudinal connectivity in hydromorphological quality assessments of rivers. The ICF index: A river connectivity index and its application to Catalan rivers. Limnetica 2011, 30, 273-292.

29. Harris, J.H.; Kingsford, R.T.; Peirson, W.; Baumgartner, L.J. Mitigating the effects of barriers to freshwater fish migrations: The Australian experience. Mar. Freshw. Res. 2016, 68, 614-628. [CrossRef]

30. Kemp, P.S.; O'Hanley, J.R. Procedures for evaluating and prioritising the removal of fish passage barriers: A synthesis. Fisheries Manag. Ecol. 2010, 17, 297-322. [CrossRef]

31. Katopodis, C.; Gervais, R. Fish Swimming Performance Database and Analyses. Available online: http://www.dfo-mpo.gc.ca/ csas-sccs / Publications / ResDocs-DocRech/2016/2016_002-eng.html (accessed on 3 January 2021).

32. Newton, M.; Dodd, J.A.; Barry, J.; Boylan, P.; Adams, C.E. The impact of a small-scale riverine obstacle on the upstream migration of Atlantic Salmon. Hydrobiologia 2017, 806, 251-264. [CrossRef]

33. Costa, M.J.; Boavida, I.; Almeida, V.; Cooke, S.J.; Pinheiro, A.N. Do artificial velocity refuges mitigate the physiological and behavioural consequences of hydropeaking on a freshwater Iberian cyprinid? Ecohydrology 2018, 11, e1983. [CrossRef]

34. Romão, F.; Santos, J.M.; Katopodis, C.; Pinheiro, A.N.; Branco, P. How Does Season Affect Passage Performance and Fatigue of Potamodromous Cyprinids? An Experimental Approach in a Vertical Slot Fishway. Water 2018, 10, 395. [CrossRef]

35. Stoot, L.J.; Cairns, N.A.; Cull, F.; Taylor, J.J.; Jeffrey, J.D.; Morin, F.; Mandelman, J.W.; Clark, T.D.; Cooke, S.J. Use of portable blood physiology point-of-care devices for basic and applied research on vertebrates: A review. Conserv. Physiol. 2014,2 , cou011. [CrossRef]

36. Barton, B.A. Stress in Fishes: A diversity of responses with particular reference to changes in circulating corticosteroids. Integr. Comp. Biol. 2002, 42, 517-525. [CrossRef]

37. Moreira, M.; Costa, M.J.; Valbuena-Castro, J.; Pinheiro, A.N.; Boavida, I. Cover or Velocity: What Triggers Iberian Barbel (Luciobarbus Bocagei) Refuge Selection under Experimental Hydropeaking Conditions? Water 2020, 12, 317. [CrossRef]

38. Farrell, A.P. Comparisons of swimming performance in rainbow trout using constant acceleration and critical swimming speed tests. J. Fish. Biol. 2008, 72, 693-710. [CrossRef]

39. White, A.J.; Schreer, J.F.; Cooke, S.J. Behavioral and physiological responses of the congeneric largemouth (Micropterus salmoides) and smallmouth bass (M. dolomieu) to various exercise and air exposure durations. Fish. Res. 2008, 89, 9-16. [CrossRef]

40. Oliveira, I.C.; Alexandre, C.M.; Quintella, B.R.; Almeida, P.R. Impact of flow regulation for hydroelectric production in the movement patterns, growth and condition of a potamodromous fish species. Ecohydrology 2020, 13, e2250. [CrossRef]

41. Amaral, S.D.; Quaresma, A.L.; Branco, P.; Romão, F.; Katopodis, C.; Ferreira, M.T.; Pinheiro, A.N.; Santos, J.M. Assessment of retrofitted ramped weirs to improve passage of potamodromous fish. Water 2019, 11, 2441. [CrossRef]

42. Enders, E.C.; Gessel, M.H.; Williams, J.G. Development of successful fish passage structures for downstream migrants requires knowledge of their behavioural response to accelerating flow. Can. J. Fish. Aquat. Sci. 2009, 66, 2109-2117. [CrossRef]

43. Amaral, S.D.; Branco, P.; Silva, A.T.; Katopodis, C.; Viseu, T.; Ferreira, M.T.; Pinheiro, A.N.; Santos, J.M. Upstream passage of potamodromous cyprinids over small weirs: The influence of key-hydraulic parameters. J. Ecohydraulics 2016, 1, 79-89. [CrossRef]

44. Amaral, S.D.; Branco, P.; Katopodis, C.; Ferreira, M.T.; Pinheiro, A.N.; Santos, J.M. Passage Performance of Potamodromous Cyprinids over an Experimental Low-Head Ramped Weir: The Effect of Ramp Length and Slope. Sustainability 2019, $11,1456$. [CrossRef]

45. Vogt, J.; Soille, P.; De Jager, A.; Rimaviciute, E.; Mehl, W.; Foisneau, S.; Bodis, K.; Dusart, J.; Paracchini, M.L.; Haastrup, P.; et al. A Pan-European River and Catchment Database; European Commission-Joint Research Centre-Institute for Environment and Sustainability: Luxembourg, 2007.

46. [CEN] European Committee for Standardization. Water Quality: Sampling of Fish. with Electricity; The European Standard EN 14011; European Committee for Standardization: Brussels, Belgium, 2003.

47. Santos, J.M.; Ferreira, M.T.; Godinho, F.N.; Bochechas, J. Efficacy of a nature-like bypass channel in a Portuguese lowland river. J. Appl. Ichthyol. 2005, 21, 381-388. [CrossRef]

48. Benitez, J.-P.; Ovidio, M. The influence of environmental factors on the upstream movements of rheophilic cyprinids according to their position in a river basin. Ecol. Freshw. Fish. 2018, 27, 660-671. [CrossRef] 
49. Dinno, A. dunn.test: Dunn's Test of Multiple Comparisons Using Rank Sums. R Package Version 1.2.3. 2015. Available online: http: / /CRAN.R-project.org/package=dunn.test (accessed on 30 November 2019).

50. R Core Team. R: A Language and Environment for Statistical Computing; R Foundation for Statistical Computing: Vienna, Austria, 2017. Available online: http:/ / www.R-project.org/ (accessed on 30 November 2019).

51. Anderson, M.J.; Gorley, R.N.; Clarke, K.R. PERMANOVA+ For. PRIMER: Guide to Software and Statistical Methods; PRIMER-E: Plymouth, UK, 2008.

52. Anderson, M.J. A new method for non-parametric multivariate analysis of variance. Austral. Ecol. 2001, 26, 32-46. [CrossRef]

53. Anderson, M.J. Permutational Multivariate Analysis of Variance (PERMANOVA). Wiley Statsref Stat. Ref. Online 2017. [CrossRef]

54. Muraoka, K.; Nakanishi, S.; Kayaba, Y. Boulder arrangement on a rocky ramp fishway based on the swimming behavior of fish. Limnologica 2017, 62, 188-193. [CrossRef]

55. Plesiński, K.; Bylak, A.; Radecki-Pawlik, A.; Mikołajczyk, T.; Kukuła, K. Possibilities of fish passage through the block ramp: Model-based estimation of permeability. Sci. Total Environ 2018, 631-632, 1201-1211. [CrossRef] [PubMed]

56. Johnson, K.; Wait, L.E.; Monk, S.K.; Rader, R.; Hotchkiss, R.H.; Belk, M.C. Effects of substrate on movement patterns and behavior of stream fish through culverts: An experimental approach. Sustainability 2019, 11, 470. [CrossRef]

57. Montali-Ashworth, D.; Vowles, A.S.; De Almeida, G.; Kemp, P.S. Use of Cylindrical Bristle Clusters as a novel multispecies fish pass to facilitate upstream movement at gauging weirs. Ecol. Eng. 2020, 143, 105634. [CrossRef]

58. Costa, M.J.; Lennox, R.J.; Katopodis, C.; Cooke, S.J. Is there evidence for flow variability as an organism-level stressor in fluvial fish? J. Ecohydraulics 2017, 2, 68-83. [CrossRef]

59. Flodmark, L.E.W.; Urke, H.A.; Halleraker, J.H.; Arnekleiv, J.V.; Vollestad, L.A.; Poléo, A.B.S. Cortisol and glucose responses in juvenile brown trout subjected to a fluctuating flow regime in an artificial stream. J. Fish. Biol. 2002, 60, 238-248. [CrossRef]

60. Kieffer, J.D. Limits to exhaustive exercise in fish. Comp. Biochem. Phys. A 2000, 126, 161-179. [CrossRef]

61. Gleeson, T.T. Post-exercise lactate metabolism: A comparative review of sites, pathways, and regulation. Annu. Rev. Physiol. 1996, 58, 565-581. [CrossRef] [PubMed] 